\title{
Methods: A Comparative Analysis of Radiography, Microcomputed Tomography, and Histology for Bone Tissue Engineering
}

\author{
ELIZABETH L. HEDBERG, Ph.D., ${ }^{1}$ HENRIETTE C. KROESE-DEUTMAN, Ph.D., ${ }^{2}$ \\ CHARLES K. SHIH, Ph.D., ${ }^{1}$ JEREMY J. LEMOINE, Ph.D., ${ }^{1}$ \\ MICHAEL A.K. LIEBSCHNER, Ph.D., ${ }^{1}$ MICHAEL J. MILLER, Ph.D., ${ }^{3}$ \\ ALAN W. YASKO, Ph.D., ${ }^{4}$ ROGER S. CROWTHER, Ph.D., ${ }^{5}$ DARRELL H. CARNEY, Ph.D., 5 \\ ANTONIOS G. MIKOS, Ph.D., ${ }^{1}$ and JOHN A. JANSEN Ph.D. ${ }^{2}$
}

\begin{abstract}
This study focused on the assessment of radiography, microcomputed tomography, and histology for the evaluation of bone formation in a $15.0-\mathrm{mm}$ defect in the rabbit radius after the implantation of a tissue-engineered construct. Radiography was found to be useful as a noninvasive method for obtaining images of calcified tissue throughout the time course of the experiment. With this method, however, image quality was low, making it difficult to obtain precise information about the location and quantity of the bone formed. Microcomputed tomography was used to create three-dimensional reconstructions of the bone $(25-\mu \mathrm{m}$ resolution). These reconstructions allowed for greater spatial resolution than the radiography, but did not allow for imaging of the implanted scaffold material or the surrounding, nonmineralized tissue. To visualize all materials within the defect area at the cellular level, histology was used. Histological analysis, however, is a destructive technique that did not allow for any further analysis of the samples. Each technique examined here has its own advantages and limitations, but each yields unique information regarding bone regeneration. It is only through the use of all three techniques that complete characterization of the bone growth and tissue/construct responses after implantation in vivo.
\end{abstract}

\section{INTRODUCTION}

$\mathbf{R}$ ESEARCHERS IN THE AREA OF TISSUE ENGINEERING have made significant progress toward the regeneration of natural, functional tissue within bone defect sites. A large number of materials have been identified as potential candidates for use as scaffolds for cellular ingrowth and/or as carriers of osteoinductive entities such as osteogenic cell populations, growth factors, and cytokines. Initial studies to evaluate the scaffold characteristics often occur in vitro. In vivo studies must also be conducted, however, for a complete understanding of the material and its ability to assist in bone formation. Naturally, in vivo studies are typically more expensive and time consuming than in vitro studies. In addition, sample numbers are limited because of ethical considerations in the use of living animals. It is

\footnotetext{
${ }^{1}$ Department of Bioengineering, Rice University, Houston, Texas.

${ }^{2}$ Department of Biomaterials, University Medical Center Nijmegen, Nijmegen, The Netherlands.

${ }^{3}$ Department of Plastic Surgery, University of Texas M.D. Anderson Cancer Center, Houston, Texas.

${ }^{4}$ Department of Orthopaedic Oncology, University of Texas M. D. Anderson Cancer Center, Houston, Texas.

${ }^{5}$ Chrysalis BioTechnology, Galveston, Texas.
} 
imperative, therefore, that proper analytical techniques be chosen for in vivo studies in order to obtain the most accurate and complete information possible.

Radiographic and histological techniques are the traditional methods employed for the assessment of bone growth into defect sites treated with tissue-engineering constructs. As radiographs are nondestructive, they are valuable for monitoring the formation of bone within a defect site over time, through the use of standard serial radiographs. Nevertheless, radiographs are two-dimensional representations of three-dimensional structures and their interpretation can be difficult. In addition, the spatial resolution of conventional radiography is low and excludes a detailed analysis of tissue structures. Histological techniques involve the analysis of two-dimensional slices prepared from tissue samples. Through the use of proper staining techniques important features such as bone, fibrous tissue, blood vessels, and cells can be identified. Measuring histomorphometric parameters such as percent bone fill and bone area coverage can yield quantitative results. By analyzing multiple histological sections from the same sample, results are often extrapolated to the three-dimensional structure. This extrapolation, however, can result in incorrect three-dimensional reconstructions because of the anisotropic nature of bone.

An alternative to plane radiographs and histology is microcomputed tomography $(\mu \mathrm{CT}) . \mu \mathrm{CT}$ is a nondestructive imaging technique that is easy to perform. Using a fine-beam X-ray source and a two-dimensional detector array, the sample is slowly rotated as the X-ray source projects through the sample. The data collected from these projections are processed into a two-dimensional image. The process is repeated, generating a series of two-dimensional images through the length of the specimen. Computer algorithms are then used to reconstruct the internal and external structure of the sample from the many two-dimensional images collected. Quantitative results can also be obtained, including bone volume and surface area-to-volume ratios. $\mu$ CTs employing conventional X-ray sources have a resolution down to 10 $\mu \mathrm{m}$, whereas equipment using synchrotron radiation has a resolution down to $1 \mu \mathrm{m} .{ }^{1-3}$ Differences in attenuation coefficients between bone, fibrous tissue, and polymeric implants allow for reconstruction of bone independent of the surrounding materials. ${ }^{4}$

The aim of the current study is to compare the various available analytical techniques for the assessment of bone ingrowth into defects treated with tissue-engineered constructs and to examine their advantages and disadvantages. To perform this analysis, poly(propylene fumarate)-based scaffolds carrying the osteogenic peptide TP508 (Chrysalin; MW 2311; AGYKPDEGKRGDACEGDSGGPFV) with different release profiles and doses were implanted into $15.0-\mathrm{mm}$ defects in the rabbit radius. The classes employed in this study included (1) scaffolds loaded with $200 \mu \mathrm{g}$ of TP508 exhibiting a large burst release (LB200); (2) scaffolds loaded with $200 \mu \mathrm{g}$ of TP508 exhibiting a minimal burst release (MB200); (3) scaffolds loaded with $100 \mu \mathrm{g}$ of TP508 exhibiting a minimal burst release (MB100); and, (4) blank scaffolds without TP508 (NR). ${ }^{5}$ Individual samples were monitored by radiography, microcomputed tomography, and histology, allowing for comparison of the different techniques with each sample.

\section{MATERIALS AND METHODS}

\section{Polymer synthesis}

Poly(propylene fumarate) (PPF) and the cross-linking molecule poly(propylene fumarate)-diacrylate (PPF-DA) were synthesized as previously described. ${ }^{6}$

\section{Microparticle fabrication}

Microparticles of 50:50 poly(DL-lactic-co-glycolic acid) (PLGA) (Medisorb; Alkermes, Cambridge, MA) loaded with TP508 (Chrysalis BioTechnology, Galveston, TX) were prepared by a double-emulsion, solvent extraction technique ([water-in-oil]-in water) as previously described. ${ }^{6}$ Briefly, $125 \mu \mathrm{L}$ of aqueous solution $(15.0 \mathrm{mg}$ of TP508 in distilled deionized $\mathrm{H}_{2} \mathrm{O}$ ) was injected into a flint glass tube containing $235.0 \mathrm{mg}$ of the PLGA in $1 \mathrm{~mL}$ of dichloromethane. This mixture was emulsified on a vortexer (Vortex-Genie 2; Scientific Industries, Bohemia, $\mathrm{NY}$ ). The first emulsion was then combined with $1.5 \mathrm{~mL}$ of $0.3 \%$ aqueous polyvinyl alcohol (PVA) solution (Aldrich Chemical, Milwaukee, WI) with vortexing, producing a second emulsion. This second emulsion was added to 100 $\mathrm{mL}$ of $0.2 \%$ aqueous isopropanol (Fisher Chemicals, Fairlawn, NJ) and $98.5 \mathrm{~mL}$ of $0.3 \%$ aqueous PVA with rapid stirring for $1 \mathrm{~h}$. Microparticles were collected by centrifugation at $180 \times g$ for $1 \mathrm{~min}$, lyophilized to dryness, and stored at $-40^{\circ} \mathrm{C}$ until use. The final product consisted of spherical microparticles with a mass loading of $0.066 \mathrm{~g}$ of TP508 per gram of microparticles as determined by an established solvent extraction technique. ${ }^{7}$ Blank microparticles were fabricated as outlined above, with omission of the TP508 from the initial aqueous solution.

To achieve the proper dose in each scaffold class without altering the proportion of microparticles to polymer in the composite scaffolds, TP508-loaded microparticles were combined with blank, unloaded microparticles. The mixtures prepared contained 44 and 22\% loaded microparticles per mass for scaffolds containing 200 and $100 \mu \mathrm{g}$ of TP508, respectively.

\section{PPF composite scaffold fabrication}

Four classes of PPF composite scaffolds were fabricated for this study (Table 1). For all classes, scaffolds 
Table 1. Properties of PPF/Plga Composite Scaffold Classes

\begin{tabular}{lcccc}
\hline & $L B 200^{\mathrm{a}}$ & $M B 200^{\mathrm{b}}$ & $M B 100^{\mathrm{c}}$ & $N^{\mathrm{d}}$ \\
\hline TP508 dose $(\mu \mathrm{g})$ & 200 & 200 & 100 & 0 \\
Location of microparticles & Pores & Polymer & Polymer & phase \\
Preleaching & phase & No & No & phase \\
Pluronic F127 & Yes & No & No & No \\
\hline
\end{tabular}

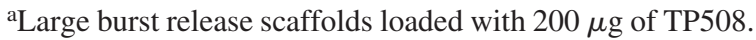

${ }^{\mathrm{b}}$ Minimal burst release scaffolds loaded with $200 \mu \mathrm{g}$ of TP508.

${ }^{\mathrm{c}}$ Minimal burst release scaffolds loaded with $100 \mu \mathrm{g}$ of TP508.

${ }^{\mathrm{d} C}$ Control scaffolds: no release of TP508.

were thermally cross-linked with the free radical initiator benzoyl peroxide (BP; Aldrich Chemical). An initiator solution was prepared by dissolving $1 \mathrm{~g}$ of BP in 10 $\mathrm{mL}$ of diethyl fumarate. PPF was mixed with PPF-DA (the double bond ratio of PPF:PPF-DA was 1:2) in the presence of $\mathrm{CH}_{2} \mathrm{Cl}_{2}$ and stirred overnight at room temperature to ensure proper mixing of the two viscous solutions. After removal of the solvent from the polymer, the initiator solution $(0.05 \mathrm{~mL} / \mathrm{g}$ polymer $)$ was added to the mixture with rapid stirring. For formulations in which the PLGA microparticles were located within the polymeric component of the scaffolds (MB200, MB100, and $\mathrm{NR}$ ), microparticle mixtures ( $0.09 \mathrm{~g}$ of microparticles per gram of polymer) were mixed into the polymer until homogeneously dispersed. All formulations then received 4 $\mathrm{g}$ of the water-soluble porogen $\mathrm{NaCl}$ per gram of the polymer-microparticle mixture. Finally, the resulting paste was placed on a Teflon plate and $1.6 \mu \mathrm{L}$ of $N, N$-dimethyl$p$-toluidine (DMT) per gram of polymer was kneaded into the mixture. The material was inserted into Teflon molds (diameter, $4.3 \mathrm{~mm}$ ) and placed in a $37^{\circ} \mathrm{C}$ oven for 20 min. After cross-linking, scaffolds were removed from the molds. MB200, MB100, and NR samples were cut to a length of $15.0 \mathrm{~mm}$ and stored under nitrogen at $4^{\circ} \mathrm{C}$. LB200 samples were placed in distilled deionized $\mathrm{H}_{2} \mathrm{O}$ for 3 days to remove the $\mathrm{NaCl}$ porogen, dried, and stored under nitrogen at $4^{\circ} \mathrm{C}$. All PPF composite materials were sterilized by exposure to ultraviolet (UV) light for $12 \mathrm{~h}$ before scaffold fabrication. All subsequent material handling occurred under sterile conditions. The complete scaffolds were exposed to UV light for an additional $12 \mathrm{~h}$ after fabrication.

\section{Microparticle solution preparation}

A solution of Pluronic F127 (PF127, 24 wt\% in distilled deionized $\mathrm{H}_{2} \mathrm{O}$; BASF, Mount Olive, $\mathrm{NJ}$ ) was made for use as a carrier for the PLGA microparticles for injection into the pores of the PPF scaffolds to fabricate LB200 samples. The use of a Pluronic solution was chosen for this study because of its unique property to be- have as a liquid at low temperatures $\left(0^{\circ} \mathrm{C}\right)$ and to form and remain as a gel at temperatures at and above room temperature. Before surgery, the cold $\left(0^{\circ} \mathrm{C}\right) \mathrm{PF} 127$ solution was added to a vial containing PLGA microparticles (0.150 g of microparticles per $2 \mathrm{~mL}$ of PF127 solution).

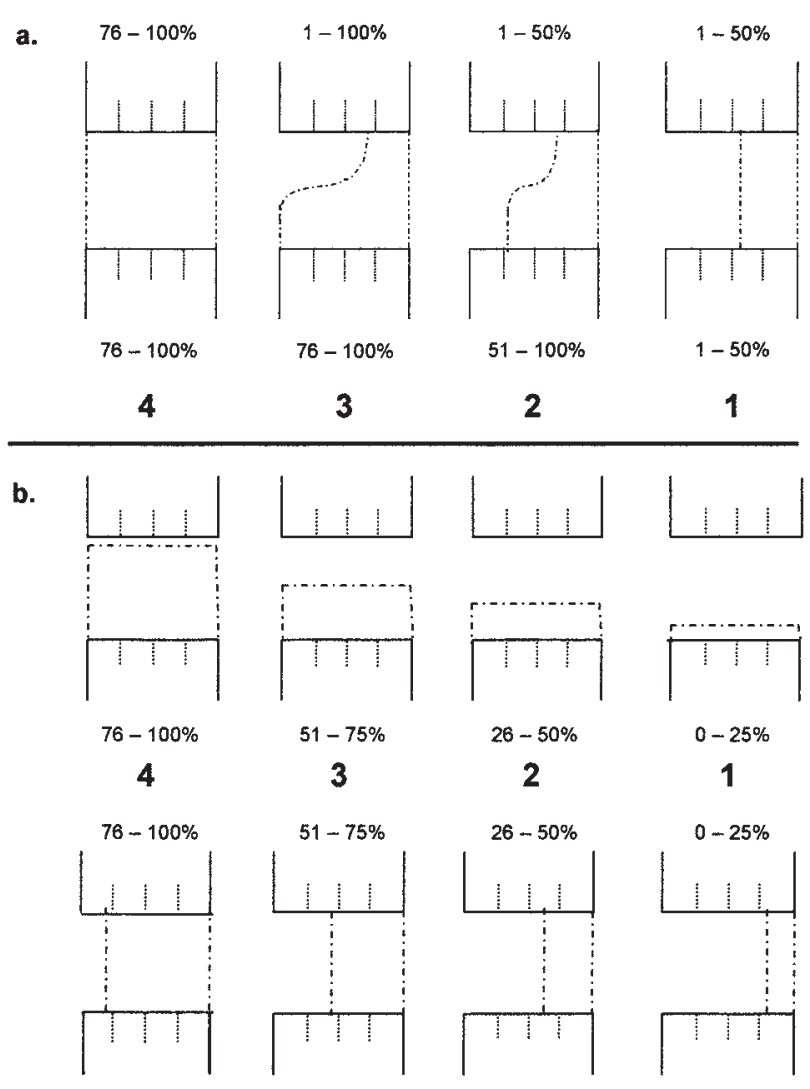

FIG. 1. Schematics used to guide investigators in the quantitative evaluation of radiographs. (a) Radiographic evaluation of the degree of union. Percentage values refer to the percentage of the given defect border that is filled with bone that spans the defect. (b) Radiographic evaluation of bone formation in the defect. Percentage values refer to the percentage of the defect area that is filled with bone. 
Table 2. Histological Grading Scale

\begin{tabular}{lc}
\hline Descriptor & Value \\
\hline $\begin{array}{l}\text { Bridging of defect border } \\
\text { (longitudinal sections) }\end{array}$ & \\
Yes & 1 \\
No & 0 \\
Presence of guided bone growth & \\
$\quad$ (cross-sectional sections) & 1 \\
Yes & 0 \\
No & \\
Extent of guided bone growth & \\
(longitudinal sections) & \\
$75-100 \%$ & 4 \\
$50-74 \%$ & 3 \\
$25-49 \%$ & 2 \\
$1-24 \%$ & 1 \\
$0 \%$ & 0 \\
\hline
\end{tabular}

${ }^{\mathrm{a}}$ Guided bone growth is a measure of the distance the guided bone growth extends from the defect border toward the center of the defect.

The microparticle solution was kept on ice until just before implantation, when it was shaken gently to obtain a homogeneous solution without creating air bubbles. The well-mixed suspension $(75 \mu \mathrm{L})$ was taken up in a syringe and injected into the pores of the polymer scaffold.

\section{Surgical procedure}

Ten healthy, female New Zealand White rabbits weighing between 2.5 and $3.5 \mathrm{~kg}$ were used in this study. Surgery was performed under general inhalation anesthesia. The anesthesia was induced by an intravenous injection of Hypnorm (fentanyl citrate $[0.315 \mathrm{mg} / \mathrm{mL}]$ and fluanisone $[10 \mathrm{mg} / \mathrm{mL}])$ and atropine and maintained with a mixture of nitrous oxide, isoflurane, and oxygen through a constant volume ventilator. Antibiotic prophy- laxis (enrofloxacin [2.5\% Baytril], $5-10 \mathrm{mg} / \mathrm{kg}$ ) was given to reduce the risk of perioperative infection.

Animals were placed in a ventral position and immobilized on their abdomen for surgery. Hair from both front limbs of each animal was shaved and the skin was disinfected with povidone-iodine. A $4.5-\mathrm{cm}$ longitudinal incision was made in the skin with a blade along the radius. Dissection of the muscle exposed the radius. The periosteum was removed and a $15.0-\mathrm{mm}$ defect was created in the middle of the radius by a burr with a diamond blade with continuous saline cooling. The samples were inserted in the defect without external fixation. Finally, the muscle layers and then the skin were closed with 4-0 Vicryl sutures. All surgeries were conducted by the same investigator at the same time.

A total of 20 scaffolds were implanted: 5 LB200, 5 MB200, 5 MB100, and 5 NR. A balanced split-plot randomization scheme was used to locate the scaffolds so that the limb choice or formulation pairing would not influence the outcome. ${ }^{8}$ At 12 weeks postimplantation, animals were euthanized with an overdose of Nembutal (pentobarbital). All implants and surrounding tissue were retrieved en bloc. The Dutch and United States National Institutes of Health Guidelines for the Care and Use of Laboratory Animals were observed throughout the course of this study.

\section{Radiography}

Under anesthesia, each rabbit was positioned prone with the forelimbs externally rotated. Serial radiographs of both forelimbs were made 0,2 , and 12 weeks postoperatively on a Mobilett X-ray machine (Siemens, Munich, Germany).

Radiographs obtained at 12 weeks were evaluated according to a modified scoring system (Fig. 1) for defect bridging and bone formation by two clinicians who were blinded to the implant type. ${ }^{9-12}$ As little to no bone formation was observed in the 0 - and 2-week radiographs,
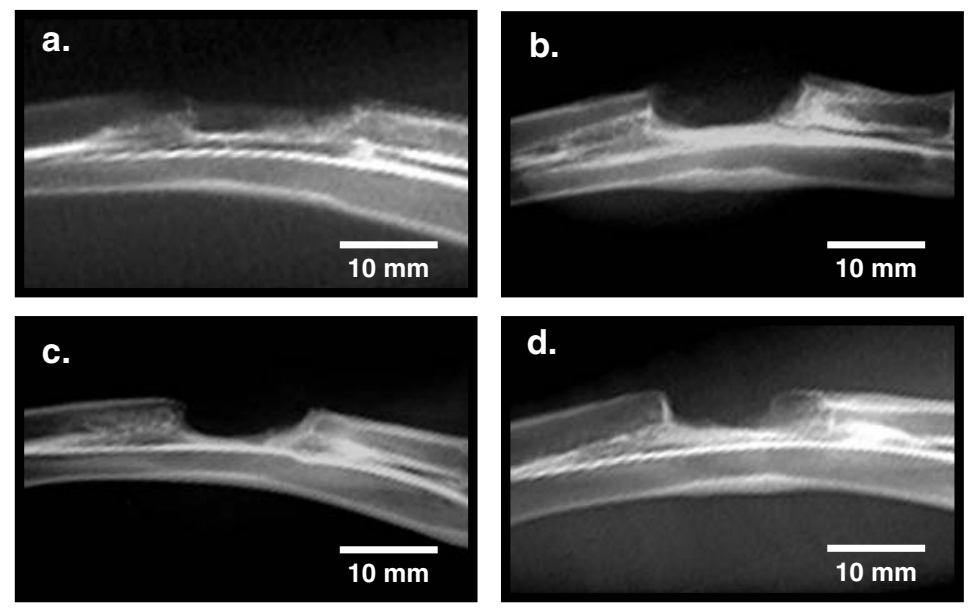

FIG. 2. Representative radiographs from each scaffold class, taken 12 weeks postoperatively. (a) LB200; (b) MB200; (c) MB100; (d) NR. 
a.

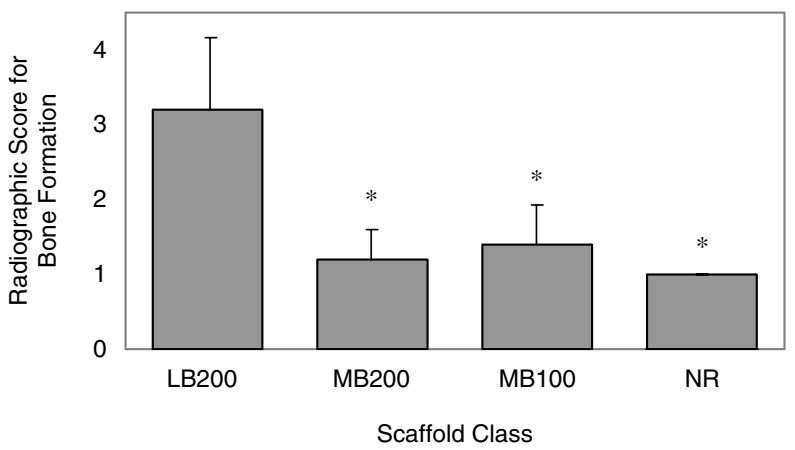

b.

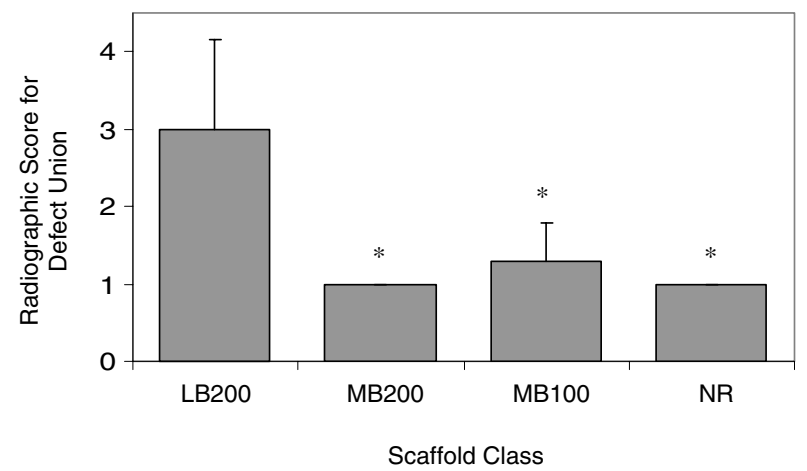

FIG. 3. Results from radiographic scoring for the amount of bone formation (a) and the degree of union (b) within the defect edges. Results represent means \pm standard deviation for $n=5$; *significant difference $(p<0.05)$ from LB200 samples.

these time points were used as negative controls to assist in the location of the original defect site in the radiographs obtained at the later time point.

On the basis of the radiographic assessment, 10 scaffolds were selected for further evaluation by both $\mu \mathrm{CT}$ and histology. The selected samples included five LB200 samples (designated group A) and two MB200 samples, two MB100 samples, and one NR sample (designated group B). The choice was based on the amount of bone ingrowth in the defect space, where group A samples displayed significantly more bone ingrowth than group B samples (minimal ingrowth).

\section{Sample harvest}

At 12 weeks postimplantation, all animals were euthanized and the defect area and surrounding tissue was retrieved. After retrieval, samples including surrounding tissue were fixed in $10 \%$ formalin solution. After fixation, specimens were placed in phosphate-buffered saline (PBS) and stored at $4^{\circ} \mathrm{C}$ until further analysis.

\section{Microcomputed tomography}

Before analysis of the samples began, a thresholding analysis was conducted on a single specimen to optimize the equipment test conditions for quantification of bone volume. ${ }^{13,14}$ Briefly, the threshold value was varied between 200 and 350 and the change in bone volume was measured. A minimum change in bone volume with varying threshold level suggested the optimal threshold value of 275 for this study.

For one run of a single scanning cycle on the $\mu \mathrm{CT}$ ( $\mu$ CT 80; SCANCO Medical, Bassersdorf, Switzerland), five specimens were fixed vertically within the sample holder filled with PBS and placed in the $\mu \mathrm{CT}$ specimen chamber. Specimens were scanned at an energy of $50 \mathrm{kV}$ and an intensity of $80 \mu \mathrm{A}$, with a nominal resolution of $25 \mu \mathrm{m}$. A long integration time $(300 \mathrm{~ms})$ was used in order to reduce the signal-to-noise ratio in the presence of the surrounding tissue and PBS.

Radiographs and gross analysis of the specimens were used to locate the defect borders. Scanning of the samples began just above the upper defect border and con- a.

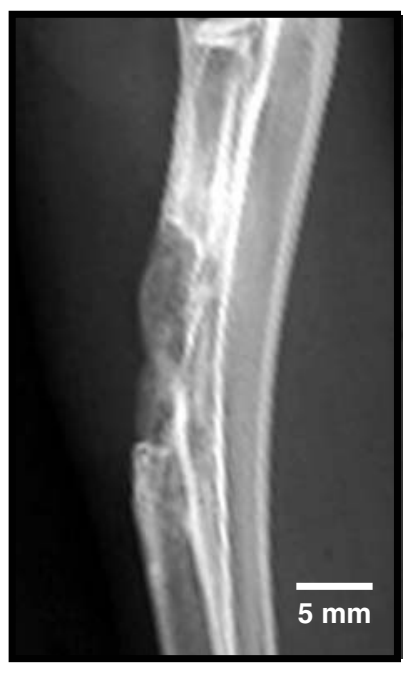

b.

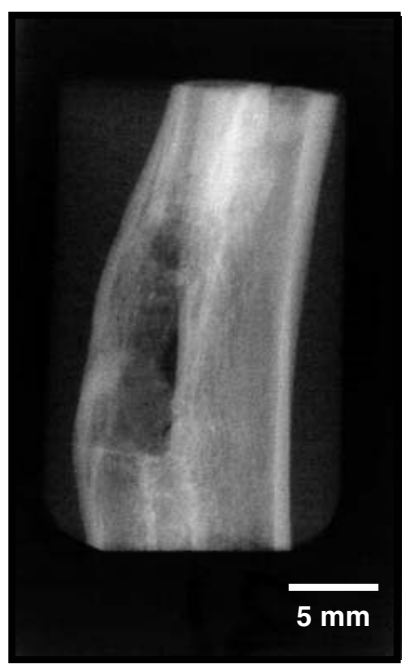

FIG. 4. Radiographs of representative sample from group A: radiograph in (a) was taken before sacrifice 12 weeks postoperatively; radiograph in (b) was taken after removal of surrounding soft tissue and embedding in methylmethacrylate. 
tinued for $20 \mathrm{~mm}$ in order to ensure inclusion of the entire defect area. The full three-dimensional (3-D) reconstructions and 12-week radiographs were then used to determine the location of the defect area more precisely. Next, the ulna and radius were isolated and reconstructed between the defect edges to obtain the ulna-radius complex. Finally, the radius was isolated from the ulna-radius complex and reconstructed independently.

\section{Histology}

After analysis by $\mu \mathrm{CT}$, specimens were dehydrated in a graded series of ethanol (from 70 to $100 \%$ [v/v]) and embedded in methylmethacrylate. After polymerization, additional radiographs were taken of each sample to assist in location of the defect borders. Subsequently, samples were hemisectioned through the center of the defect area, creating two separate samples for each implant. A series of $10-\mu \mathrm{m}$-thick sections was made axially through one implant sample and transversely through the second implant sample. ${ }^{15}$ Sections were stained with methylene blue-basic fuchsin and examined by light microscopy (Leica, Rijswijk, The Netherlands). At least three sections per sample were evaluated for (1) the presence of guided bone formation along the outer surface of the polymer scaffold, using cross-sectional sections, and (2) bone bridging of the defect borders and the extent of bone formation outside the polymer scaffold, using longitudinal samples. Two observers (M.J.M. and A.W.Y.) who were blinded to the implant type conducted the evaluations, using a modified scoring system (Table 2). The reviewers reached a consensus on the score of each section and then assigned a final score to each scaffold. The scores of the scaffolds of each class were then averaged to determine the overall score for the class.

Further histomorphometric analysis of bone ingrowth into the various specimens was performed to determine the distance bone grew into the PPF scaffolds. Again, at least three histological sections were imaged and, using a Leica QWin Pro image analysis system, the edges of the defect border were determined and the distance of bone growth into the defect was measured.

\section{Statistical analysis}

For analysis of full radiographic data, a one-way analysis of variance (ANOVA) followed by a Tukey-Kramer multiple comparisons test was used to determine statistical significance with $95 \%$ confidence intervals $(p<$ $0.05)$, using InStat version 3.05 statistical software (GraphPad, San Diego, CA). For comparison of methods, a two-tailed $t$ test was used. All results are reported as means \pm standard deviation for $n=5$.

\section{RESULTS}

\section{Complete radiographic analysis}

Radiographic analysis was performed as a noninvasive means to assess bone formation within the defect sites. Radiographs were taken just after surgery and at 2 and 12 weeks. Representative radiographs from 12 weeks postoperatively from each scaffold class are depicted in Fig. 2. The polymeric scaffolds are not visible because of the low X-ray attenuation coefficient of polymers. As
FIG. 5. $\mu \mathrm{CT}$ reconstructions of representative sample from group A: (a) position 1; (b) rotated $180^{\circ}$; (c) longitudinal section; (d) cross-sectional section. a.

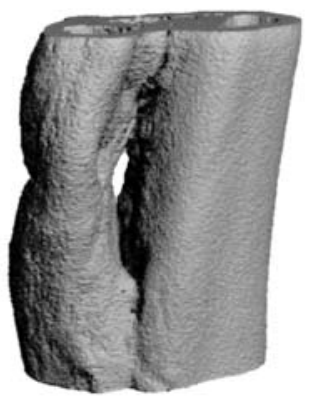

c.

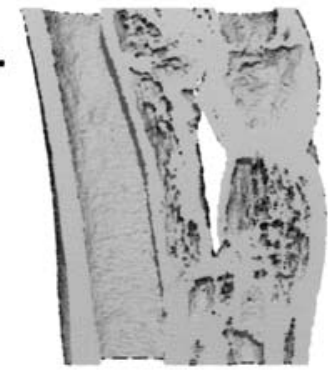

b.

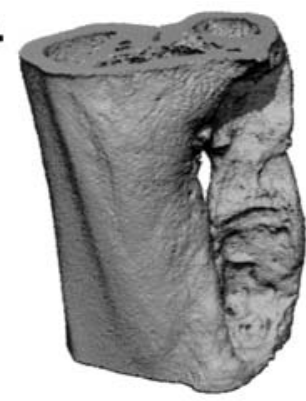

d.

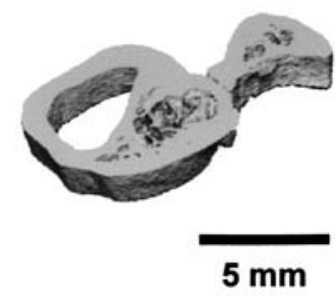


bone formation was not apparent in any of the samples at 2 weeks, radiographic scoring was performed on 12 week images only. Blinded radiographic evaluation of bone area coverage and bone union shows that implants with a large initial release of TP508 (LB200) obtain higher scores $(p<0.05)$ for both parameters than do implants with extended release (MB200 and MB100) or no release (NR) (Fig. 3).

\section{Comparative analysis using radiography, microcomputed tomography, and histology}

Group A: descriptive. Radiographs from a representative group A sample are depicted in Fig. 4. In this sample, the two-dimensional radiographs suggest full bridging of the defect as well as almost complete bone fill within the defect area. Varying densities of the radiograph indicate differing amounts of mineralization within the defect area, with a greater amount of mineralization occurring along the outside of the defect area than in the center.

Microcomputed tomography was used to create threedimensional images of the defect area as well as to determine the quantity of bone formed. Images of mineralized bone excluding surrounding tissue and polymer implant were obtained without apparent difficulty, as the attenuation coefficient for bone is much greater than that of the other materials. Representative reconstructions for the radius and ulna between the defect edges from the same representative sample can be found in Fig. 5. The comparative analysis by $\mu \mathrm{CT}$ versus radiography can best be explained with the help of the $\mu \mathrm{CT}$ image shown in Fig. 5, which is of the same specimen as the radiograph presented in Fig. 4. This radiograph suggests that bone is spanning from one defect border to the other, covering almost the entire defect area. This observation corresponds well with the $\mu \mathrm{CT}$ picture. In addition, the gap in bone between the radius and ulna seen in the radio- a.

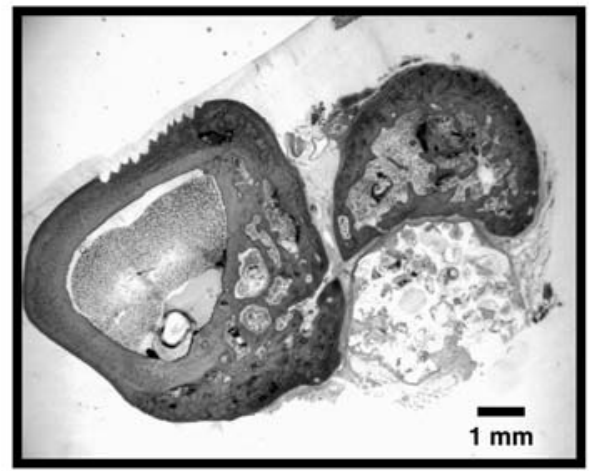

b.

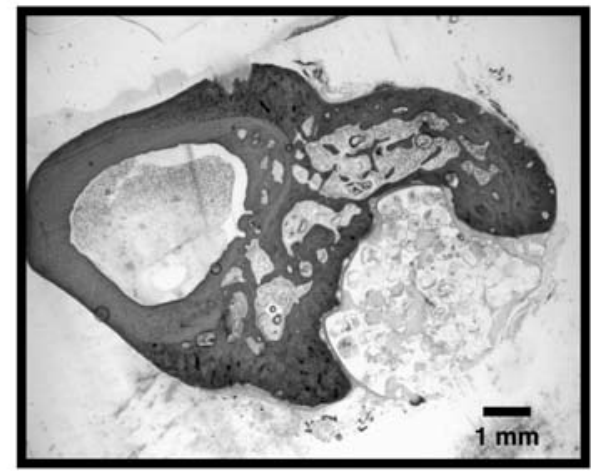

c.

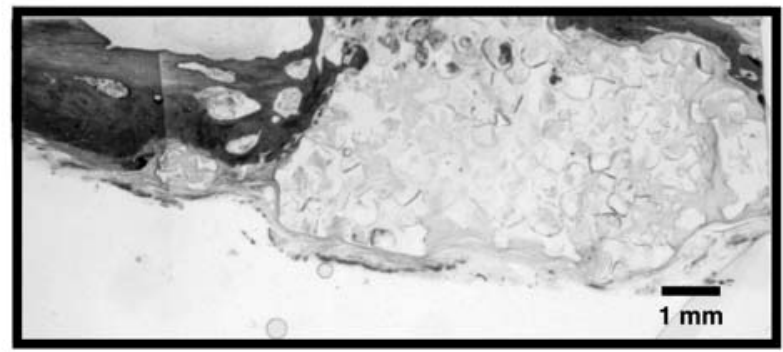

d.

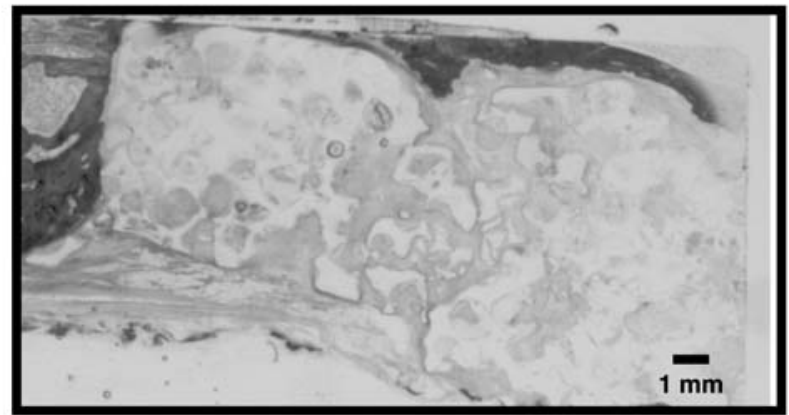

FIG. 6. Histological sections of representative sample from group A: (a and b) cross-sectional sections; (c and d) longitudinal sections of the implant. Bone overgrowth can be observed on top of the implant samples in (c) and (d). 
graph is also evident in these $\mu \mathrm{CT}$ images. On the other hand, when the sample is rotated $180^{\circ}$, it is apparent that bone formation was not uniform within the defect area (Fig. 5b). From this angle, large areas without bone can be observed. The shape of the empty area suggests the location of the polymer scaffold, but this cannot be verified by this technique. $\mu \mathrm{CT}$ also allows the creation of longitudinal as well as cross-sectional planar sections of the complete sample (Fig. $5 \mathrm{c}$ and d, respectively). Bone growth along the outside edge of the cylindrical implant can be seen. The newly formed bone, although not exactly located where the original radius had been, has a macroscopic structure similar to that of the original radius, with a dense exterior and the formation of a central canal. Finally, ulnar hypertrophy can also be observed in the cross-sectional images. Comparison of all available $\mu \mathrm{CT}$ images with the radiographs showed similar observations.

Last, $10-\mu \mathrm{m}$-thick slices were made from the samples for analysis by histological techniques. In these sections, remaining PPF polymer can easily be detected as the polymer remains unstained and appears white by light microscopy. Cross-sectional sections (Fig. 6a and b) allowed for localization and characterization of bone growth outside the scaffold as these sections allowed for complete visualization of the circumferential perimeter of the implant. Longitudinal sections revealed that bone ingrowth into the scaffold from the edge of the guided growth was limited (Fig. 6c and d). Further, these longitudinal sections allowed localization of the defect border and the measurement of the extent of bone penetration into the scaffold. All images in Fig. 6 are histological sections of the same specimen as shown in the radiograph in Fig. 4 and the $\mu$ CT images in Fig. 5. Provided that the proper direction of sectioning is chosen (cross-sectional versus longitudinal), similar information can be obtained by histology compared with $\mu \mathrm{CT}$.

Group B: descriptive. Radiographs, $\mu \mathrm{CT}$ reconstructions, and histological images for a representative sample from group B can be found in Fig. 7. All techniques show minimal bone growth in the defect area. However, only evaluation of the histological sections provides information about the remaining polymer as well as about the tissue and cell populations within the pores of the scaffold.

Groups A and B: quantitative. Quantitative data for all specimens, using radiography, $\mu \mathrm{CT}$, as well as histology, are summarized in Table 3 . Samples were assigned to groups according to their radiographic evalua-

\section{a.}

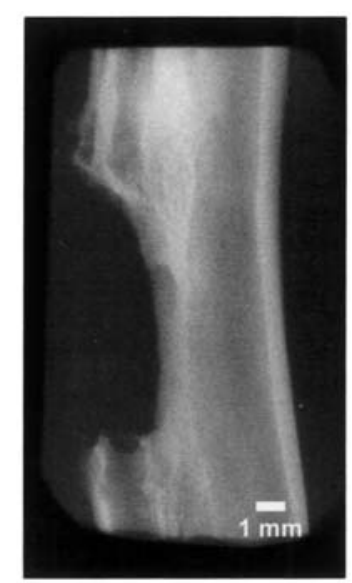

c.

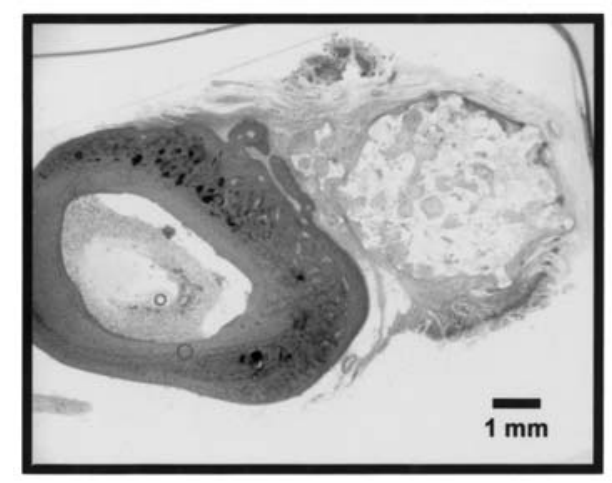

b.

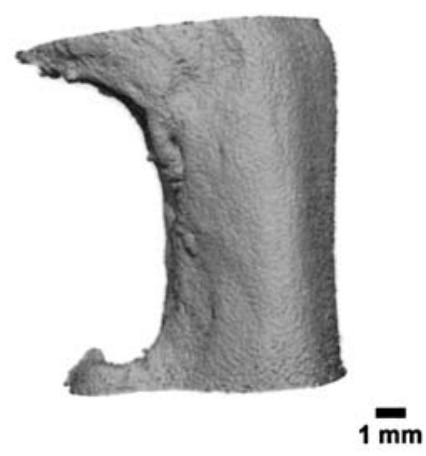

d.

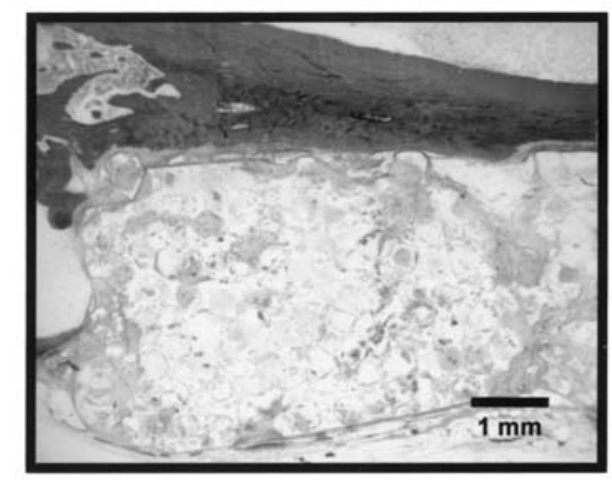

FIG. 7. Radiography (a), $\mu \mathrm{CT}$ (b), and histology (c and $\mathbf{d}$ ) images of a representative sample from group B. 
Table 3. Quantitative Results of All Samples

\begin{tabular}{|c|c|c|c|c|c|c|c|c|c|c|c|c|}
\hline & \multicolumn{6}{|c|}{ Group $A^{\mathrm{a}}$} & \multicolumn{6}{|c|}{ Group $B^{\mathrm{b}}$} \\
\hline & $A 1$ & $A 2$ & $A 3$ & A4 & $A 5$ & Mean & $B 1$ & $B 2$ & $B 3$ & $B 4$ & B5 & Mean \\
\hline \multicolumn{13}{|l|}{ Radiography scoring } \\
\hline Fill & 4 & 4 & 2 & 4 & 4 & $3.6 \pm 0.9^{c}$ & 1 & 1 & 1 & 1 & 1 & $1.0 \pm 0.0^{c}$ \\
\hline Union & 4 & 4 & 1 & 4 & 4 & $3.4 \pm 1.3^{\mathrm{c}}$ & 1 & 1 & 1 & 1 & 1 & $1.0 \pm 0.0^{\mathrm{c}}$ \\
\hline \multicolumn{13}{|l|}{$\mu \mathrm{CT}$} \\
\hline $\begin{array}{l}\text { Bone volume } \\
\text { per mm } \\
\left(\mathrm{mm}^{3} / \mathrm{mm}\right)\end{array}$ & 18.3 & 13.9 & 12.1 & 11.1 & 7.4 & $12.6 \pm 4.0^{c}$ & 5.7 & 4.5 & 3.3 & 2.3 & 2.2 & $3.6 \pm 1.5^{\mathrm{c}}$ \\
\hline \multicolumn{13}{|l|}{ Histology scoring ${ }^{\mathrm{d}}$} \\
\hline Bridging & 1 & 0 & 1 & 1 & 0 & $0.6 \pm 0.5^{\mathrm{e}}$ & 0 & 0 & 0 & 0 & 0 & $0.0 \pm 0.0^{\mathrm{e}}$ \\
\hline $\begin{array}{l}\text { Guided bone } \\
\text { growth } \\
\text { (cross- } \\
\text { sectional) }\end{array}$ & 1 & 1 & 1 & 1 & 1 & $1.0 \pm 0.0$ & 1 & 1 & 0 & 1 & 1 & $0.8 \pm 0.5$ \\
\hline $\begin{array}{l}\text { Guided bone } \\
\text { growth } \\
\text { (longitudinal) }\end{array}$ & 4 & 4 & 1 & 4 & 4 & $3.4 \pm 1.3^{\mathrm{c}}$ & 0 & 2 & 0 & 0 & 1 & $0.6 \pm 0.9^{c}$ \\
\hline $\begin{array}{l}\text { Penetration } \\
\text { distance } \\
(\mathrm{mm})\end{array}$ & 7.5 & 0 & 1.3 & 3.3 & 0 & $2.4 \pm 3.1$ & 0 & 0 & 0 & 0 & 0 & $0.0 \pm 0.0$ \\
\hline
\end{tabular}

${ }^{\mathrm{a}}$ Group A is composed of samples that displayed radiographic union at week 12.

${ }^{\mathrm{b}}$ Group B is composed of samples that did not display radiographic union at week 12 .

${ }^{\mathrm{c}}$ Significant difference between group A and group $\mathrm{B}, p<0.01$.

${ }^{\mathrm{d}}$ Histology scoring scales for bridging, guided bone growth can be found in Table 2.

eSignificant difference between group A and group B, $p<0.05$.

tion. Group A samples showed more bone formation and defect bridging than did group B samples. Results from the $\mu \mathrm{CT}$ measurements support this finding, with more bone volume per unit length in the group A samples than in the group B samples.

Samples A1, A2, A4, and A5 had radiographic scores of 4 for both parameters examined, indicating complete closure of the defect. In contrast, results from $\mu \mathrm{CT}$ and histology both show that complete closure of the defect area was not obtained. It is only through the application of these additional techniques that a clear understanding of the location and structure of the regenerated tissue is obtained. On the other hand, results from radiography, $\mu \mathrm{CT}$, and histology all yielded the same results in samples with minimal bone formation.

\section{DISCUSSION}

In vivo experiments are a necessary step in the characterization of potential materials for bone tissue-engineering applications. These studies can be costly and time consuming, so each experiment must be carefully planned and executed in order to maximize the amount of information gathered. In the present work, three analytical techniques currently available for the assessment of bone formation were used for evaluation of bone ingrowth in segmental radius defects after the implantation of a biodegradable polymer scaffold that released osteogenic peptides at varied release rates and dosages.

Ten samples were selected for complete analysis by all three techniques. Five of those specimens showed radiographically complete bone filling of the defect area after 12 weeks of implantation, whereas the five remaining specimens showed little to no bone fill at all after the same time period.

Our results show that each method explored in this study, that is, radiography, microcomputed tomography, and histology, can be used to gather unique information regarding tissue-engineering scaffolds and their ability to assist in the regeneration of bone tissue. Radiographs are useful as a noninvasive method for the imaging of tissues with high X-ray attenuation coefficients such as bone. Within less than $1 \mathrm{~h}$ an image of the gross structure of bone inside a living animal can be obtained. The animal can be imaged repeatedly, allowing for the visualization of a defect area multiple times over the course of an implantation period. Polymers do not usually appear in radiographs as they have low X-ray attenuation coefficients. ${ }^{16}$ This can be an advantage as it allows for 
an unobstructed view of mineralized tissue growth into a defect area. Unfortunately, it does not allow for visual localization of the implant within the defect site, which can be useful when movement or prolonged maintenance of the implant is a potential problem. Additives such as barium sulfate, supplemented to the polymer before fabrication of the scaffold, can solve this visualization problem. However, it must be noted that such additives may interfere with the tissue response. ${ }^{16-18}$ Metals and ceramics have higher attenuation coefficients and can be easily recognized in radiographic images. ${ }^{12,19}$

Interpretation of X-ray images is not necessarily a simple process. Therefore, evaluation of radiographs must always be done by multiple experienced evaluators. Each point on a plane radiographic image is a function of the attenuation coefficients of all materials through which the $\mathrm{X}$-ray beam passes. This results in the mapping of a threedimensional object onto a two-dimensional image. This loss of the three-dimensional structure results in a loss of depth information, making it impossible to determine the precise location of a feature. ${ }^{20}$ Consequently, guided bone growth around a scaffold will always be difficult to distinguish from bone ingrowth into a tissue-engineered construct.

Microcomputed tomography is a relatively new, nondestructive technique for imaging bone in three dimensions. As with plane radiographs, X-rays are directed at a sample and a detector on the far side of the object detects the emitted signal. With $\mu \mathrm{CT}$, however, this process is repeated multiple times as the sample rotates $180^{\circ}$ at each two-dimensional vertical level of the sample and a complex algorithm is used to determine the structure at that level. This method produces hundreds of two-dimensional images from which a three-dimensional image can be extracted by the appropriate computer analysis software.

Without the need for any specimen preparation, $\mu \mathrm{CT}$ was found to produce good-quality topographical images of our samples that can be rotated and viewed from any angle. In all our images, bone was easily distinguishable from nonbone (polymer and soft tissue) because of the differences in their X-ray attenuation coefficients. An ad-

Table 4. Comparison of Radiography, Microcomputed Tomography, and Histology

\begin{tabular}{|c|c|c|c|}
\hline & Radiography & $\begin{array}{c}\text { Microcomputed } \\
\text { tomography }\end{array}$ & Histology \\
\hline Advantages & $\begin{array}{l}\text { Nondestructive } \\
\text { Performable on live } \\
\text { animals } \\
\text { Fast } \\
\text { Easy to perform } \\
\text { Serial images of a given } \\
\text { sample over time } \\
\text { No visualization of tissue- } \\
\text { engineering construct }\end{array}$ & $\begin{array}{l}\text { Nondestructive } \\
\text { Fast } \\
\text { Easy to perform } \\
\text { Three-dimensional } \\
\text { images } \\
\text { Areas of interest } \\
\text { can be isolated and } \\
\text { imaged independently } \\
\text { Direct measurement } \\
\text { of bone volume } \\
\text { Easy quantification } \\
\text { of multiple bone- } \\
\text { related parameters } \\
\text { Isolation of bone } \\
\text { from surrounding soft } \\
\text { tissue and remaining } \\
\text { polymer }\end{array}$ & $\begin{array}{l}\text { Visualization of } \\
\text { polymer and } \\
\text { different tissue } \\
\text { types } \\
\text { Cellular-level } \\
\text { imaging } \\
\text { Semiquantitative }\end{array}$ \\
\hline Disadvantages & $\begin{array}{l}\text { 2-D images of 3-D } \\
\text { structures } \\
\text { Training required for } \\
\text { proper interpretation } \\
\text { Low spatial resolution } \\
\text { Administration of } \\
\text { anesthesia required for } \\
\text { live subjects } \\
\text { Difficult to quantity } \\
\text { results } \\
\text { No visualization of } \\
\text { polymer without the use } \\
\text { of additives }\end{array}$ & $\begin{array}{l}\text { Large amount of } \\
\text { electronic data need } \\
\text { to be stored } \\
\text { Resolution at supra- } \\
\text { cellular level } \\
\text { Difficult with living } \\
\text { tissue; possible } \\
\text { damage to DNA at } \\
\text { required X-ray } \\
\text { doses }\end{array}$ & $\begin{array}{l}\text { Destructive } \\
\text { Labor intensive } \\
\text { Time consuming } \\
\text { 2-D images of 3-D } \\
\text { structures } \\
\text { Results dependent } \\
\text { on direction and } \\
\text { angle of sectioning } \\
\text { Difficult to quantify } \\
\text { results }\end{array}$ \\
\hline
\end{tabular}


ditional advantage is that nondestructive sectioning of the sample can be done in all directions for visualization of the bone structure within the defect site. The use of $\mu \mathrm{CT}$ also allows for quantitative measurements of many parameters important for the characterization of bone. Moreover, $\mu \mathrm{CT}$ allows quantitative characterization of the architecture of porous biodegradable polymer scaffolds ${ }^{13,14}$ and can be used for the measurement of mineral deposits on cell-scaffold constructs cultured in vitro. ${ }^{21}$ For all types of bone samples, bone volume can be measured directly. For trabecular samples, important indices such as surface area, trabecular thickness, trabecular spacing, and trabecular number can also be determined directly. ${ }^{4}$ As with plane radiographs, however, visualization of a polymer is not possible within a tissue environment. ${ }^{4}$ In addition, the resolution of $\mu \mathrm{CT}$ is at the supracellular level and cannot be used to obtain detailed information about the cellular bone-healing response. Even if and when the resolution of microcomputed tomography reaches the cellular level, the low $\mathrm{X}$-ray attenuation coefficient of cells will still render visualization impossible. ${ }^{4}$

Histological analysis is commonly employed for analysis of bone structure after retrieval of a specimen. With this technique, samples are embedded in methylmethacrylate and cut into $10-\mu \mathrm{m}$-thick sections. Sections can be stained for visualization of specific features such as bone, fibrous tissue, blood vessels, and cells. Qualitative analysis is obtained by viewing the sections under a light microscope. Unlike with radiographs and $\mu \mathrm{CT}$ reconstructions, histology allows for visualization and characterization of the microscopic nature of the tissue in and around an implant. Resolution is such that individual cells can be seen in a histological section.

Quantitative results can be obtained through the use of computer-based histomorphometric measurements. Here again, two-dimensional representations of a three-dimensional object must be employed. To overcome this limitation, serial sections can be obtained and 3-D reconstructions can be made with the assistance of stereomicroscopy. Loss of large quantities of tissue (up to hundreds of microns) is not uncommon during sectioning. The reconstructions, therefore, are just estimations of the real structure of the sample. Histological techniques certainly offer a better representation of the three-dimensional structure of bone tissue than plane radiographs. They are, however, much more labor intensive and time consuming. In addition, histology is a destructive technique that does not allow for further testing of a given sample or for corrections when, for example, the wrong direction of sectioning is chosen.

\section{CONCLUSIONS}

Radiography, microcomputed tomography, and histology all have associated advantages and limitations
(Table 4). Each technique, however, gives important information regarding the in vivo response to the implantation of tissue-engineering constructs. Used together, they work in cooperation to yield the most complete understanding of tissue formation and regeneration.

\section{ACKNOWLEDGMENTS}

The authors acknowledge financial support from NWO-AGIKO (920-030175) (H.C.K.) and from the Nanoscale Science and Engineering Initiative of the National Science Foundation (EEC-0118001) and the National Institutes of Health (RO1-DE15164 and RO1AR42639) (A.G.M.).

\section{REFERENCES}

1. Muller, B., Thurner, P., Beckmann, F., Weitkamp, T., Rau, C., Bernhardt, R., Karamuk, E., Eckert, L., Brandt, J., Buchlon, S., Winter, E., Scharnweber, D., and Worch, H. Non-destructive three-dimensional evaluation of biocompatible materials by microtomography using synchrotron radiation. In: Bonse, U., ed. Developments in X-Ray Tomography III. San Diego, CA: SPIE Press, 2002, pp. 178-188.

2. Salome, M., Peyrin, F., Cloetens, P., Odet, C., Laval-Jeantet, A.M., Baruchel, J., and Spanne, P. A synchrotron radiation microtomography system for the analysis of trabecular bone samples. Med. Phys. 26, 2194, 1999.

3. Weiss, P., Obadia, L., Magne, D., Bourges, X., Rau, C., Weitkamp, T., Khariou, I., Bouler, J.M., Chappard, D., Gauthier, O., and Daculsi, G. Synchrotron X-ray microtomography (on microscale) provides three-dimensional imaging representation of bone ingrowth in calcium phosphate biomaterials. Biomaterials 24, 4591, 2003.

4. Hidebrand, T., Laib, A., Muller, R., Dequeker J., and Ruegsegger P. Direct three-dimensional morphometric analysis of human cancellous bone: Microstructural data from spine, femur, illiac crest, and calcaneus. J. Bone Miner. Res. 14, 1167, 1999.

5. Hedberg, E.L., Kroese-Deutman, H.C., Shih, C.K., Crowther, R.S., Carney, D.H., Mikos, A.G., and Jansen, J.A. Effect of varied release kinetics of the osteogenic thrombin peptide TP508 from biodegradable, polymeric scaffolds on bone formation in vivo. J. Biomed. Mater. Res. A 72A, 343, 2005.

6. Hedberg, E.L., Tang, A., Crowther, RS, Carney, D.H., and Mikos, A.G. Controlled release of an osteogenic peptide from injectable biodegradable polymeric composites. J. Control. Release 84, 137, 2002.

7. Lu, L., Stamatas, G.N., and Mikos, A.G. Controlled release of transforming growth factor- $\beta_{1}$ from biodegradable polymeric microparticles. J. Biomed. Mater. Res. 30, 440, 2000.

8. Jansen, J.A., and van't Hof, M.A. Histological assessment of sintered metal-fibre-web materials. J. Biomater. Appl. 9, 31, 1994. 
9. Bos, G.D., Powell, A.E., Heiple, K.G., and Zika, J.M. The effect of histocompatibility matching on canine frozen bone allografts. J. Bone Joint Surg. 65A, 89, 1983.

10. Yang, C.Y., Simmons, D.J., and Lozano, R. The healing of grafts combining freeze-dried and demineralized allogenic bone in rabbits. Clin. Orthop. Relat. Res. 298, 286, 1994.

11. Lane J.M., and Sandhu, H.S. Current approaches to experimental bone grafting. Orthop. Clin. North Am. 18, 213, 1987.

12. Johnson, K.D., Frierson, K.E., and Keller, T.S.Porous ceramics as bone graft substitutes in long bone defects: A biomechanical, histological, and radiographic analysis. J. Orthop. Res. 14, 351, 1996.

13. Behravesh, E., Timmer, M.D., Lemoine, J.J., Liebschner, M.A.K., and Mikos, A.G. Evaluation of the in vitro degradation of macroporous hydrogels using gravimetry, confined compression testing, and microcomputed tomography. Biomacromolecules 3, 1263, 2002.

14. Hedberg, E.L., Shih, C.K., Lemoine, J.J., Timmer, M.D., Liebschner, M.A.K., Jansen, J.A., and Mikos, A.G. In vitro degradation of poly(propylene fumarate)/poly(DL-lacticco-glycolic acid) composite scaffolds. Biomaterials 26, 3215, 2005.

15. van der Lubbe, H.B., Klein, C.P., and deGroot, K.A. A simple method for preparing thin $(10 \mu \mathrm{m})$ histological sections of undecalcified plastic embedded bone with implants. Stain Technol. 63, 171, 1988.

16. Lasarus, M.D., Cuckler, J.M., Schumacher, H.R.J., Ducheyne, P., and Baker, D.G. Comparison of the inflammatory response to particulate polymethylemethacrylate debris with and without barium sulfate. J. Orthop. Res. 12, 532, 1994.

17. Sabokar, A., Fujikawa, Y., Murray, D.W., and Athanasiou, N.A. Radio-opaque agents in bone cement increase bone resoption. J. Bone Joint Surg. Br. 79, 129, 1997.

18. Wimhurst, J.A., Brooks, R.A., and Rushton, N. The effects of particulate bone cements at the bone-implant interface. J. Bone Joint Surg. Br. 83, 588, 2001.

19. van Oosterwyck, H., Duyck, J., Vander Perre, G., Jansen, J.A., Wevers, M., and Naert, I. The use of microfocus computerized tomography as a new technique for characterizing bone tissue around oral implants. J. Oral Implant. 26, 5, 2000.

20. Davis, G.R., and Wong, F.S.L. X-ray microtomography of bones and teeth. Physiol. Meas. 17, 121, 1996.

21. Sikavitsas, V.I., Bancroft, G.N., Lemoine, J.J., Liebschner, M.A.K., Dauner, M., and Mikos A.G. Flow perfusion enhances the calcified matrix deposition of marrow stromal cells in biodegradable non-woven fiber mesh scaffolds. Ann. Biomed. Eng. 33, 63, 2005.

Address reprint requests to: John A. Jansen, Ph.D. University Medical Center Department of Periodontology and Biomaterials P.O. Box 9101 6500 HB Nijmegen, The Netherlands

E-mail: j.jansen@dent.umcn.nl 